\title{
Relationship between the functional status constructs and quality of life in COPD
}

\author{
Relação entre dimensões do estado funcional \\ e qualidade de vida na DPOC
}

\section{Karoliny dos Santos ${ }^{[a]}$, Manuela Karloh ${ }^{[b]}$, Cintia Laura Pereira de Araujo ${ }^{[c]}$, Andrezza Brognoli D'Aquino ${ }^{[\mathrm{d}]}$, Anamaria Fleig Mayer ${ }^{[\mathrm{e}]}$}

[a] MSc candidate, Universidade do Estado de Santa Catarina, Programa de Pós-Graduação em Fisioterapia, Florianópolis, SC - Brazil, e-mail: fisio.karoliny@gmail.com

[b] MSc, professor, Universidade do Estado de Santa Catarina, Departamento de Fisioterapia, Florianópolis, SC - Brazil, e-mail: manukarloh@gmail.com

[c] MSc, Universidade do Estado de Santa Catarina, Programa de Pós-Graduação em Fisioterapia, Florianópolis, SC - Brazil, e-mail: cintia_lpa@yahoo.com.br

[d] Graduate, Universidade do Estado de Santa Catarina, Florianópolis, SC - Brazil, e-mail: dezzadaquino@globo.com

[e] PhD, professor, Universidade do Estado de Santa Catarina, Programa de Pós-Graduação em Fisioterapia, Florianópolis, SC - Brazil, e-mail: anafmayer@udesc.br

\section{Abstract}

Introduction: Functional status is an important component of health related quality of life (QOL) in patients with chronic obstructive pulmonary disease (COPD). However there is a lack of studies aiming to evaluate the association between QOL and the different methods for assessing patient's limitation to perform ADL. Objectives: To investigate the association between QOL and functional status, measured by four different instruments: London Chest Activity of Daily Living scale (LCADL), six-minute walking test (6MWT), Glittre ADL-test (TGlittre) and assessment of physical activities in daily living (PADL). Methods: Twenty-three patients with COPD, GOLD 2 to 4, were submitted to the following evaluations: spirometry, the Saint George Respiratory Questionnaire (SGRQ), LCADL, 6MWT, TGlittre and assessment of PADL. Pearson or Spearman correlation coefficients were used to verify the association between the variables. Results: It was observed correlation between all domains of the SGRQ and the 6MWT, between TGlittre and 'leisure' domain of LCADL; and between the domain 'activity' of the SGRQ with the total score of LCADL ( $r=0.53)$, LCADL\% $(r=$ 
$0.54)$, 'self care' $(r=0.49)$ and 'leisure' $(r=0.82)$. The number of steps correlated with the SGRQ $(r=-0.59)$ and with 'activity' $(\mathrm{r}=-0.70)$ and 'impact' $(\mathrm{r}=-0.52)$ domains. The standing time correlated with the domain 'activitiy' ( $r=-0.47$ ) of the SGRQ ( $p<0.05$ for all). Conclusions: Both functional performance and capacity are able to reflect the impact that ADL limitation has on QOL in patients with COPD

Keywords: Chronic obstructive pulmonary disease. Quality of life. Activities of daily living.

\section{Resumo}

Introdução: $O$ estado funcional é um componente importante da qualidade de vida (QV) relacionada à saúde em pacientes com doença pulmonar obstrutiva crônica (DPOC). Entretanto há uma escassez de estudos associando a QV com os diversos métodos de avaliação das limitações em atividades de vida diária (AVD). objetivos: Verificar se existe associação entre QV e estado funcional, mensurado por diferentes métodos: escala London Chest Activity of Daily Living (LCADL), Teste de Caminhada de Seis Minutos (TC6min), Teste de AVD-Glittre (TGlittre) e monitorização das atividades físicas de vida diária (AFVD). Métodos: 23 pacientes com DPOC, GOLD 2 a 4, submetidos às avaliações: espirometria, questionário de QV, Questionário Saint George na Doença Respiratória (SGRQ), escala LCADL, TC6min, TGlittre e monitorização das AFVD. Coeficientes de correlação de Pearson ou Spearman foram utilizados para verificar associação entre as variáveis. Resultados: Verificou-se correlação entre todos os domínios do SGRQ e o TC6min, entre o TGlittre e domínio 'lazer' da escala LCADL; entre o domínio 'atividades' do SGRQ e o escore total da escala LCADL ( $r=0,53), L C A D L \%$ total $(r=$ $0,54)$ e com seus domínios 'cuidados pessoais' $(r=0,49)$ e 'lazer' $(0,82)$. O número de passos se correlacionou com SGRQ $(r=-0,59)$, com 'atividades' $(r=-0,70)$ e 'impacto' $(r=-0,52)$; o tempo em pé correlacionou-se com o domínio 'atividades' $(r=-0,47)$ do SGRQ ( $p<0,05$ para todas as correlações). Conclusões: em pacientes com DPOC, tanto a capacidade quanto a performance funcional são capazes de refletir o impacto que a limitação de AVD exerce sobre a QV em pacientes com DPOC.

Palavras-chave: Doença pulmonar obstrutiva crônica. Qualidade de vida. Atividades cotidianas.

\section{Introduction}

Chronic obstructive pulmonary disease (COPD) is characterized by progressive deterioration of respiratory function over time, with systemic manifestations that lead to functional impairment, evidenced by fatigue and exercise limitation, causing negative impact on quality of life (1).

Functional and quality of life impairment are correlated with objectives physiological measures of disease severity in patients with COPD (2).

However, a large proportion of the changes in functional status - i.e. the ability to perform activities required during the normal course of someone's life that are necessary to meet basic needs, regular functions and maintain health and well-being (3) and in the quality of life cannot be explained by pulmonary physiological measures (4).

In COPD, quality of life widely reflects the impact of symptoms associated with the activities of daily living.
Functional status and dyspnea, therefore, are important components of health-related quality of life (5).

Functional capacity also seems to be one of the factors that influence quality of life in patients with COPD (6). Recent studies have demonstrated that dyspnea has negative association with quality of life $(7,8,9)$ and functional capacity $(8,9,10)$; however the magnitude of the relationship between quality of life and functional status is not clear.

Perhaps, a better performance in the six-minute walk test (6MWT) means less difficulty in performing daily physical activities and, consequently, lower impact of the disease on functional performance and quality of life. However, there is a lack of studies that associate quality of life with different measuring methods of the limitations in ADL. Also, it is not clear which ADL constructs are more related to the quality of life domains of these patients.

In this context, the present study aims to investigate the association between quality of life 
and functional status, measured by three different methods: London Chest Activity of Daily Living Scale (LCADL), which is a recall of the ADL; functional capacity tests (6MWT and Glittre ADL-test), that mimic the situations experienced in real life ADL; and monitoring physical activities of daily living (PADL), which quantify the activities performed during an usual day.

\section{Methods}

It was conducted a descriptive, cross-sectional and quantitative study with a non-probabilistic convenience sample of 23 patients (14 men) with COPD. The study included Global Initiative for Chronic Obstructive Lung Disease (GOLD) spirometric stages 2, 3, and 4 COPD patients with clinical stability in the four weeks prior to the study protocol. Individuals who were unable to perform any of the study evaluations or had associated diseases, such as cardiomyopathy, musculoskeletal diseases, tuberculosis and asthma were excluded from the sample. The study was approved by the Ethics Committee for Human Research of Santa Catarina State University and all participants signed a written informed consent form (approval number 175.491)

Patients underwent a simple anthropometric assessment in which weight and height were assessed with a calibrated scale and a stadiometer (Filizola, São Paulo, Brazil); and body mass index (BMI - weight/ height ${ }^{2}$ ) was calculated. It was also conducted pulmonary function test, the 6MWT, the Glittre-ADL Test (TGlittre), on three different days, the London Chest Activity of Daily Living Scale (LCADL), the St. George's Respiratory Questionnaire (SGRQ) and the monitoring of physical activities of daily living (PADL). PADL were monitored in 19 of 23 patients.

\section{Pulmonary function testing}

Lung function was tested using an Easy One Spirometer (NDD Medical Technologies, Suíça), which calibration was checked before each evaluation. Spirometry was performed in accordance with ATS/ERS standards (11). Forced expiratory volume in first second $\left(\mathrm{FEV}_{1}\right)$, forced vital capacity $(\mathrm{FVC})$ and $\mathrm{FEV}_{1} / \mathrm{FVC}$ ratio were obtained before and 15 minutes after inhalation of bronchodilator (Salbutamol 400 $\mu \mathrm{g})$. The predicted values were calculated from the Brazilian equations proposed by Pereira et al. (12).

\section{Six-Minute Walking Test}

The 6MWT was performed in a 20 -m long aisle following the standardized guidelines of American Thoracic Society (13). The patients were instructed to walk as far as possible, with standardized verbal encouragement repeated every minute. Two tests were carried out with an interval of 30 minutes between them and the greatest distance was considered for statistical analysis. Predicted values for walking distance were calculated according to the Brazilian equation proposed by Iwama et al. (14).

\section{Glittre-ADL Test}

The TGlittre was validated to evaluate essential but limiting activities in patients with COPD and consists of completing a circuit while carrying a weighted backpack ( $2.5 \mathrm{~kg}$ for women, $5.0 \mathrm{~kg}$ for men). The circuit is as follows: from a sitting position, the patient stands up and walks along a flat 10-m long course; in the middle of which is a 2-step staircase (each step $17 \mathrm{~cm}$ high $\times 27 \mathrm{~cm}$ deep) to be traversed; after completing the second $5 \mathrm{~m}$, the subject faces a shelf containing three objects, each weighing $1 \mathrm{~kg}$, positioned on the top shelf (shoulder height) and moves them one by one to the bottom shelf (waist height) and then to the floor; the objects are then returned to the bottom shelf and finally to the top shelf again; the patients then walk back along the circuit, climbing and descending the stairs, until reaching the starting point (chair); sitting down and immediately beginning the next lap. Patients were instructed to complete 5 laps on this circuit as quick as possible and no verbal encouragement was given (15).

\section{London Chest Activity of Daily Living Scale} (LCADL)

This scale contains four domains related to 'self care', 'domestic activities', 'physical activities', and 'leisure'. It allows evaluation of the of patient's dyspnea level and response to therapeutic intervention (16, 17). The LCADL scale involves usual ADLs such as putting on a shirt, making the bed, etc. It has a total of 15 quantitative questions in which patients can score from 0 to 5 points, thus allowing a maximum score of 75 points $\left(\mathrm{LCADL}_{\text {total }}\right.$ ) The higher the score, the greater the limitation of the patient (16). The percentage of 
the total score was also calculated (LCADL\%total), not considering items for which the answer was zero (18).

Physical activity in daily life monitoring

In order to quantify physical ADL, the patients were monitored with an accelerometer-based activity monitor (DynaPort MiniMod, McRoberts BV, The Hague, The Netherlands) for 12 hours on two consecutive days, beginning immediately after awakening. All subjects were carefully instructed on how the device should be positioned and received a manual with clear instructions. In addition, the patients were instructed to make no changes to their routine of daily activities while wearing the device (19). The time spent sitting, lying, standing and walking, the movement intensity during walking and the energy expenditure during these positions/movements were measured. Mira2 software (McRoberts BV, The Hague, The Netherlands) was used to read and process the accelerometer data.

\section{Saint George Respiratory Disease Questionnaire}

The SGRQ is a disease-specific questionnaire used to assess quality of life. It has been translated and validated for the Brazilian population and it includes three domains: 1) Symptoms: questions about the complaints related to respiratory problems (cough, sputm, shortness of breath and wheezing); 2) Activity: questions related to activities that caused shortness of breath in the last few days (bathing, sitting and walking); and 3) Impact: how the patient describes the respiratory disease and whether it interferes in functional activities (if cough and shortness of breath impair their daily activities). The total and domains score were calculated as a percentage of its maximum. Values above $10 \%$ reflect impaired quality of life (20).

\section{Statistical analysis}

The data were reported as means with standard deviations (SD) or median and interquartile range. The Shapiro-Wilk test was used to analyze data normality. Pearson's Correlation Coefficient test was performed to verify the association between the domains of the SGRQ with the following outcomes: distance walked in the 6MWT; sitting, walking and standing time and walking movement intensity. Spearman's Correlation test was done to verify the association between the scores of the SGRQ domains with TGlittre, lying time, number of steps taken and all domains of the LCADL, including the $\mathrm{LCADL}_{\text {total }}$ and LCADL\%total scores. Statistical significance was set at $\mathrm{p}<0.05$. Data analysis was performed with SPSS 20.0.

\section{Results}

Twenty-three patients were evaluated, with mean age of $65.3 \pm 7.6$ years-old. Five $(21.7 \%)$ had moderate disease (GOLD 2), 11 (47.8\%) severe (GOLD 3) and seven (30.4\%) very severe (GOLD 4). Regarding functional capacity, it was observed that patients walked, on average, $74 \%$ of the predicted value in the 6MWT and the time spent in the TGlittre was $5.43 \pm 2.14$ minutes. It was observed that patients were active in approximately $37 \%$ of the day and in the remaining time (63\%) they have adopted sedentary postures (lying or sitting). Clinical and functional characteristics of the sample are shown in Tables 1 and 2 , respectively.

It was also observed negative correlation between the scores of all domains of the SGRQ with the distance walked in 6MWT and with the time required to complete TGlittre ( $\mathrm{p}<0.05$; Table 3 and Figure 1$)$.

The domain 'activity' of the SGRQ correlated with the total score of LCADL $(r=0.53, p<0.05$, Figure $2 a)$, with LCADL\%total ( $r=0.54, p<0.05$, Figure $2 b$ ) and with LCADL domains 'self care' $(r=0.49, \mathrm{p}<0.05)$ and 'leisure' ( $r=0.82, \mathrm{p}<0.05)$.

The domain 'leisure' of the LCADL was the only one that significantly correlated with all domains of the SGRQ: 'symptoms' ( $\mathrm{r}=0.51, \mathrm{p}<0.05$ ), 'activity' $(\mathrm{r}=0.82, \mathrm{p}<0.05)$, 'impact' $(\mathrm{r}=0.60, \mathrm{p}<0.05)$ and total score $(r=0.69, p<0.05)$. Domains 'housework' and 'physical activity' were not correlated with the scores of quality of life.

Walking, sitting and lying times and walking movement intensity of PADL did not correlate with the SGRQ scores. On the other hand, the number of steps taken negatively correlated with the total score of the SGRQ $(r=-0.59, \mathrm{p}<0.05)$ and with its domains 'activity' $(\mathrm{r}=-0.70, \mathrm{p}<0.05)$ and 'impact' $(\mathrm{r}=-0.52$, $\mathrm{p}<0.05$ ). Also, the standing time correlated with the domain 'activity' $(r=-0.47, \mathrm{p}<0.05)$ of the SGRQ. 
Table 1 - Characteristics of the study group

\begin{tabular}{ccc}
\hline & & Cl 95\% \\
\cline { 3 - 3 } COPD & Mean \pm SD & (LL - UL) \\
\hline Age (years) & $65.3 \pm 7.62$ & $62.0-68.6$ \\
Weight (Kg) & $68.1 \pm 11.7$ & $63.0-73.2$ \\
Height (m) & $1.64 \pm 0.08$ & $1.60-1.68$ \\
BMI (Kg/m²) & $25.4 \pm 4.78$ & $23.3-27.5$ \\
FEV $(\mathrm{L})$ & $1.11 \pm 0.42$ & $0.92-1.29$ \\
FEV $(\%$ pred $)$ & $39.4 \pm 15.2$ & $32.8-46.0$ \\
FVC (L) & $2.40 \pm 0.66$ & $2.11-2.68$ \\
FVC (\%pred) & $65.0 \pm 17.4$ & $57.4-72.5$ \\
FEV $1 /$ FVC (\%) & $0.45 \pm 0.13$ & $0.40-0.51$ \\
\hline
\end{tabular}

Note: $\mathrm{COPD}=$ chronic obstructive pulmonary disease; Mean $\pm \mathrm{SD}(95 \% \mathrm{Cl})$; $\mathrm{LL}=$ lower limit of normality; $\mathrm{UL}=$ upper limit of normality; $\mathrm{BMI}=$ body mass index; $\mathrm{FEV}_{1}=$ forced expiratory volume in one second; $\mathrm{FVC}=$ forced vital capacity; \%pred $=\%$ predicted.

Source: Research data.

Table 2 - Functional status and quality of life

\begin{tabular}{lcc}
\hline COPD & Mean & SD \\
\hline 6MWT distance (m) & 423.4 & 83 \\
6MWT distance (\%pred) & 74.8 & 16.3 \\
TGlittre time (min) & 5.43 & 2.14 \\
LCADLtotal\# & 17 & $12-24$ \\
LCADL\%total\# & 28 & $22.2-38.6$ \\
$\quad$ Self care\# & 5 & $4-7$ \\
$\quad$ Domestic activities\# & 3 & $1-7$ \\
$\quad$ Physical activities\# & 3 & $3-4$ \\
$\quad$ Leisure\# & 4 & $3-5$ \\
SGRQ total & 41.7 & 19.7 \\
SGRQ symptoms & 32.7 & 21.1 \\
SGRQ activity & 59.7 & 21 \\
SGRQ impact & 34.3 & 22 \\
Lying time (min)\# & 63 & $21-185$ \\
Sitting time (min) & 341 & 113 \\
Standing time (min) & 152 & 45.7 \\
Walking time (min) & 103 & 39 \\
Steps\# & 4870 & $4056-8980$ \\
Movement intensity (m/s²) & 0.159 & 0.016 \\
\hline
\end{tabular}

Note: $\mathrm{COPD}=$ chronic obstructive pulmonary disease; SD $(95 \% \mathrm{Cl})=$ standart deviation; $6 \mathrm{MWT}=$ six-minute walk test; \%pred $=\%$ predicted; TGlittre $=$ Glittre-ADL test; LCADL total $=$ total score in the London Chest Activity of Daily Living scale; $L C A D L \%$ total $=$ porcentage of total score in the London Chest Activity of Daily Living scale; SGRQ = Saint George Respiratory Questionnaire; min = minutes. \#Non parametric variables - median and interquartiale range $25 \%-75 \%$.

Source: Research data. 
Table 3 - Correlation coefficient (r) between functional tests performance and quality of life domains

\begin{tabular}{llc}
\hline & $6 \mathrm{MWT}$ & TGlittre \\
\hline SGRQ total & $-0.60^{\star}$ & $0.68^{\star}$ \\
SGRQ symptoms & $-0.42^{\star}$ & $0.43^{\star}$ \\
SGRQ activities & $-0.57^{\star}$ & $0.47^{\star}$ \\
SGRQ impact & $-0.56^{\star}$ & $0.77^{\star}$ \\
\hline
\end{tabular}

Note: ${ }^{*} \mathrm{p}<0.05$.

Source: Research data.

(A)

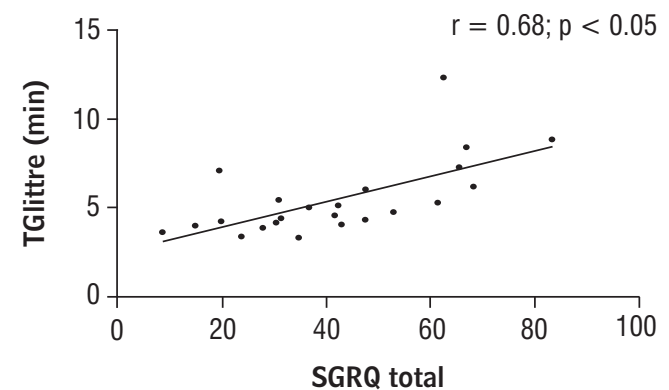

(B)

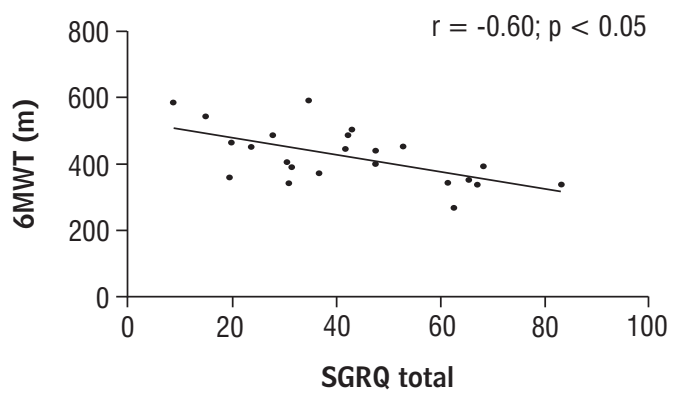

Figure 1 - A) Correlation between the SGRQ score and the time spent in Glittre ADL-test (TGlittre). (B) Correlation between the SGRQ score and six minute walking test distance (6MWT)

Source: Research data.

(A)

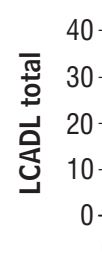

(C)

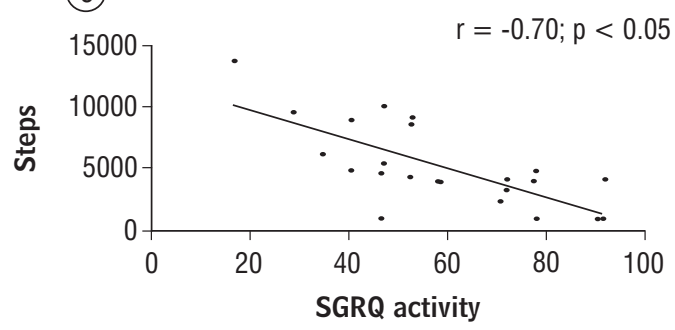

(B)

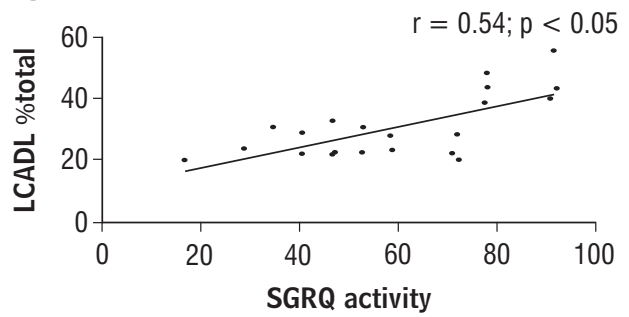

(D)

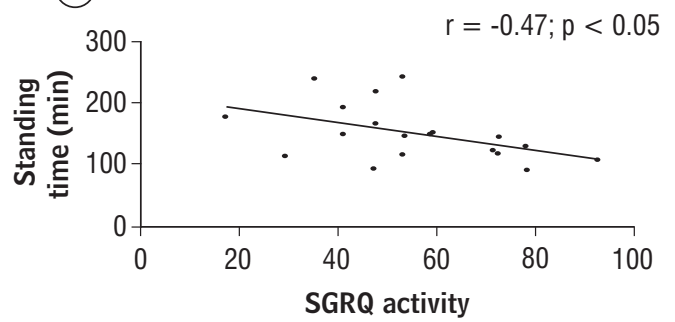

Figure 2 - (A) Correlation between the domain 'activity' of the SGRQ and the total score of the LCADL. (B) Correlation between the domain 'activity' of the SGRQ and the percentage of total score of the LCADL. (C) Correlation between the domain 'activity' of the SGRQ and the number of steps. (D) Correlation between the domain 'activity' of the SGRQ and standing time Source: Research data. 


\section{Discussion}

The present study aimed to verify the association between quality of life and the dimensions of functional status, measured by different instruments in patients with moderate, severe and very severe COPD.

Functional status is a multidimensional concept composed by four constructs: functional capacity, performance, reserve and capacity utilization. Thus, functional capacity is the maximum potential to perform activities; functional performance refers to the day-to-day activities that people actually choose and need to do during their normal routines depending to the limits imposed by the functional capacity; functional reserve is the difference between capacity and performance and refers to latent abilities that can be used if needed; and capacity utilization is the effort used to reach the functional performance (3).

Whereas there is no gold standard instrument to assess each one of the different dimensions of functional status in patients with COPD (16), the three methods most commonly used to measure functional capacity and performance - i.e. scale, field test and accelerometer-based activities monitoring - were used in the present study in order to identify which of them best reflects the impairment in quality of life.

The SGRQ was used to assess health-related quality of life because it is a disease-specific questionnaire and also because a previous study has shown that out of eleven instruments to assess quality of life in COPD, the SGRQ was the one that considered the largest number of items included in the International Classification of Functioning, Disability and Health (ICF) - a model in which functioning and disability are conceived as a dynamic interaction between health conditions and contextual factors (21).

The evaluation of health-related quality of life in patients with COPD usually includes symptoms, functional status and the impact of the disease on the individual. Thus, quality of life largely reflects the impact of symptoms that leads to ADLs performance limitations (5).

This study showed that the quality of life correlated with the walking distance in 6MWT, with the time spent in TGlittre, with the score of the LCADL scale, with the number of steps taken and with time standing time in PADL.

The 6MWT and TGlittre correlated with all domains and with the total score of the SGRQ, however TGlittre showed stronger correlation values than the 6MWT in almost all domains of quality of life. Although the 6MWT measures the functional capacity of patients with COPD (19), it includes only walking, which could induce a different metabolic expenditure and dyspnea than those induced in everyday activities. The TGlittre mimics several real-life situations with a set of usual activities performed in daily life that are troublesome for patients with COPD, including walking. This could reflect more faithfully the limitations experienced by these patients in their day-to-day (15), (22).

It was found correlation between the total score of LCADL with the domain 'activity' of the SGRQ. The domains 'domestic activities' and 'physical activities' of LCADL did not correlated with quality of life. A higher percentage of males did not perform domestic activities in the sample and scored zero in most of the items of the domain 'housework' which, in part, may have influenced the above results, showing that this is a ADL domain that does not interfere or interferes little in the quality of life of these patients. The domain 'physical activity' of the LCADL scale includes only two activities (climbing stairs and bending), which are present in only 3 out of 50 items assessed in the SGRQ. On the other hand, the domain 'leisure' of the LCADL scale correlated with all the scores of the SGRQ. Leisure activities are often the first that patients with COPD stop performing, since these activities, in general, require greater effort without being essential to the daily life (5). For this reason, these activities seem to be the ones that most early impact on the quality of life. With the disease and functional limitation progression, more essential activities, such as domestic and personal care activities, can lead greater disability, further impairing the quality of life.

Although some patients had severe disease (GOLD 3 ), they had less functional impairment than patients in other studies $(18,23,24)$, reaching on average $75 \%$ of predicted distance in 6MWT. Moreover, when compared to previous studies that have investigated PADL of patients with COPD, the patients of the present study walked more (on average $103.7 \mathrm{~min} /$ day $v s$. $55 \mathrm{~min} /$ day) (23) and spent less time lying (on average 107.2 vs. $119 \mathrm{~min} /$ day) (24), emphasizing that these patients are possibly less functionally limited than the patients in previous studies.

A recent study that evaluated end-stage disease COPD patients found that those functionally less severe had less impairment in quality of life. In addition, 
the most functionally impaired had greater impact on quality of life, especially in the domains 'activities' (25). Whereas the removal of an activity in daily life depends on the need and/or convenience and on the intensity of symptoms associated with it (5), these findings suggest that the functional status exerts greater impact on quality of life of patients in more advanced stages of the disease.

Of the $37 \%$ of the time in which the patients remained active in PADL, only 14\% of the time was spent walking. The number of steps taken correlated with the total score of the SGRQ and with its domains 'activity' and 'impact'. The standing time during PADL was associated with the domain 'activity'. Since most of the items of this domain mentions active postures, including activities that involve from bipedalism to the practice of any sport, in fact it was expected that higher level of physical activity was related to better scores in this domain.

However, multivariate analysis have shown that there are a number of variables independently associated with the level of PADL, such as gender, age, socioeconomic status, oxygen therapy, and healthrelated quality of life (26). This means that the level of PADL is influenced by many factors, and that quality of life alone does not reflect adequately the extent to which each individual is physically active in daily life (24), (26).

Some factors could be pointed as limitations of the study. Even if a methodological criterion has been followed, some subjective aspects related general health could have changed patient's perception, interfering in the assessment of quality of life. Furthermore, it is described in the literature that quality of life can be determined by a number of factors including gender, disease severity, body mass index, smoking history, comorbidities, exercise tolerance, dyspnea and exacerbations (27). Thus, despite having found significant associations between quality of life and functional status dimensions, it is important to note that many other factors affect the perception of quality of life in patients with COPD.

This was the first study to investigate the association between the quality of life and the dimensions of functional status, evaluated by different methods validated for patients with COPD. The knowledge of the association between these variables can help health professionals to guide intervention focused on the improvement of these aspects, expanding clinical goals in the treatment of COPD patients, optimizing functionality and patient's satisfaction in the domains considered relevant by themselves.

\section{Conclusion}

The quality of life in patients with COPD is associated with time spent in the Glittre-ADL test, number of steps taken, standing time, walking distance in the 6MWT and LCADL score. These data demonstrate that both functional capacity - maximum potential to develop an activity - and performance - daily activities performed - are able to reflect the impact that the impairment of activities of daily living has on the quality of life of patients with COPD.

\section{References}

1. Global Initiative for Chronic Obstructive Lung Disease. Global strategy for the diagnosis, management, and prevention of COPD. Manchester: GOLD; 2011. Available from: http://www.goldcopd.org/uploads/users/ files/GOLD_Report_2011_Feb21.pdf

2. Monso E, Fiz JM, Izquierdo J, Alonso J, Coll R, Rosell A, et al. Quality of life in severe chronic obstructive pulmonary disease: correlation with lung and muscle function. Respir Med. 1998;92(2):221-7.

3. Leidy N. Using functional status to assess treatment outcomes. Chest. 1994;106(6):1645-6.

4. Giardino ND, Curtis JL, Andrei AC, Fan VS, Benditt JO, Lyubkin M, et al. Anxiety is associated with diminished exercise performance and quality of life in severe emphysema: a cross-sectional study. Respir Res. 2010;11:29.

5. Reardon JZ, Lareau SC, ZuWallack R. Functional status and quality of life in chronic obstructive pulmonary disease. Am J Med. 2006;119(10 Suppl 1):32-7.

6. Dourado VZ, Antunes LCO, Carvalho LR, Godoy I. Influência de caractéristicas gerais na qualidade de vida de pacientes com doença pulmonar obstrutiva crônica. J Bras Pneumol. 2004;30(3):207-14.

7. Hajiro T, Nishimura K, Tsukino M, Ikeda A, Oga T, Izumi T. Comparison of the level of dyspnea vs. disease severity in indicating the health-related quality of life of patients with COPD. Chest. 1999;116(6):1632-7. 
8. Karapolat H, Eyigor S, Atasever A, Zoghi M, Nalbantgil S, Durmaz B. Effect of dyspnea and clinical variables on the quality of life and functional capacity in patients with chronic obstructive pulmonary disease and congestive heart failure. Chin Med J. 2008;121(7):592-6.

9. Akinci AC, Pinar R, Demir T. The relation of the subjective dyspnoea perception with objective dyspnoea indicators, quality of life and functional capacity in patients with COPD. J Clin Nurs. 2013;22(7-8):969-76.

10. Peruzza S, Sergi G, Vianello A, Pisent C, Tiozzo F, Manzan A, et al. Chronic obstructive pulmonary disease (COPD) in elderly subjects: impact on functional status and quality of life. Respir Med. 2003;97(6):612-7.

11. Miller MR, Hankinson J, Brusasco V, Burgos F, Casaburi R, Coates A, et al. Standardisation of spirometry. Eur Respir J. 2005;26(2):319-38.

12. Pereira CAC, Sato T, Rodrigues SC. Novos valores de referência para espirometria forçada em brasileiros adultos de raça branca. J Bras Pneumol. 2007;33(4): 397-406.

13. ATS Committee on Proficiency Stantards for Clinical Pulmanary Function Laboratories. ATS statement: guidelines for the six-minute walk test. Am J Respir Crit Care Med. 2002;166(1):111-7.

14. Iwama AM, Andrade GN, Shima P, Tanni SE, Godoy I, Dourado VZ. The six-minute walk test and body weight-walk distance product in healthy Brazilian subjects. Braz J Med Biol Res. 2009;42(11):1080-5.

15. Skumlien S, Hagelund T, Bjortuft O, Ryg MS. A field test of functional status as performance of activities of daily living in COPD patients. Respir Med. 2006; 100(2):316-23.

16. Garrod R, Bestall JC, Paul EA, Wedzicha JA, Jones PW. Development and validation of a standardized measure of activity of daily living in patients with severe COPD: the London Chest Activity of Daily Living scale (LCADL). Respir Med. 2000;94(6):589-96.

17. Garrod R, Paul EA, Wedzicha JA. An evaluation of the reliability and sensitivity of the London Chest Activity of Daily Living Scale (LCADL). Respir Med. 2002;96(9):725-30.

18. Carpes MF, Mayer AF, Simon KM, Jardim JR, Garrod R. Versão brasileira da escala London Chest Activity of daily living para uso em pacientes com doença pulmonar obstrutiva crônica. J Bras Pneumol. 2008; 34(3):143-51.
19. Pitta F, Troosters T, Spruit MA, Probst VS, Decramer M, Gosselink R. Characteristics of physical activities in daily life in chronic obstructive pulmonary disease. Am J Respir Crit Care Med. 2005;171(9):972-7.

20. Sousa TC, Jardim JR, Jones P. Validação do Questionário do Hospital Saint George na Doença Respiratória (SGRQ) em pacientes portadores de doença pulmonar obstrutiva crônica. J Pneumologia. 2000;26(3):119-28.

21. Stucki A, Stucki G, Cieza A, Schuurmans MM, Kostanjsek N, Ruof J. Content comparison of healthrelated quality of life instruments for COPD. Respir Med. 2007;101(6):1113-22.

22. Corrêa KS, Karloh M, Martins LQ Santos Kd, Mayer AF. Can the Glittre ADL test differentiate the functional capacity of COPD patients from that of healthy subjects? Rev Bras Fisioter. 2011;15(6):467-73.

23. Hernandes NA, Teixeira DC, Probst VS, Brunetto AF, Ramos EM, Pitta F. Profile of the level of physical activity in the daily lives of patients with COPD in Brazil. J Bras Pneumol. 2009;35(10):949-56.

24. Pitta F, Breyer MK, Hernandes NA, Teixeira D, Sant'Anna TJ, Fontana AD, et al. Comparison of daily physical activity between COPD patients from Central Europe and South America. Respir Med. 2009;103(3):421-6.

25. Habraken JM, van-der-Wal WM, Ter-Riet G, Weersink EJ, Toben F, Bindels PJ. Health-related quality of life and functional status in end-stage COPD: a longitudinal study. Eur Respir J. 2011;37(2):280-8.

26. Garcia-Aymerich J, Felez MA, Escarrabill J, Marrades RM, Morera J, Elosua R, et al. Physical activity and its determinants in severe chronic obstructive pulmonary disease. Med Sci Sports Exerc. 2004;36(10):1667-73.

27. Tsiligianni I, Kocks J, Tzanakis N, Siafakas N, van-derMolen T. Factors that influence disease-specific quality of life or health status in patients with COPD: a review and meta-analysis of Pearson correlations. Prim Care Respir J. 2011;20(3):257-68.

Received: 09/12/2013

Recebido: 12/09/2013

Approved: 03/16/2014

Aprovado: 16/03/2014 